\title{
OPTIMASI PERTUMBUHAN BIBIT ANGGREK Dendrobium Sp. STADIA REMAJA DENGAN PEMBERIAN GROW QUICK LB
}

\author{
SIRLYANA ${ }^{1}$, SURTINAH $^{2 *}$ \\ ${ }^{1}$ Prodi Teknik Industri Sekolah Tinggi Teknologi Dumai \\ J1. Takari No. 94. Dumai \\ ${ }^{2}$ Prodi Agroteknologi Fakultas Pertanian Universitas Lancang Kuning \\ Jl. Yos Sudarso Km. 8 Rumbai, Pekanbaru \\ e-mail: surtinah@unilak.ac.id
}

\begin{abstract}
ABSTRAK
Tujuan penelitian adalah untuk mendapatkan konsentrasi Grow Quick LB yang optimum untuk pertumbuhan bibit anggrek Dendrobium Sp. Rancangan lingkungan yang digunakan adalah Rancangan Acak lengkap. Rancangan perlakuan yang diberikan adalah konsentrasi Grow Quick $L B 0 \mathrm{cc} \mathrm{l}^{-1}$ air, 0,5 cc/l air, $1 \mathrm{cc} \mathrm{l}^{-1}$ air, 1,5 $\mathrm{cc} \mathrm{l}^{-1}$ air, $2 \mathrm{cc}$ $\mathrm{l}^{-1}$ air, dan 2,5 $\mathrm{cc}^{-1}$ air. Data yang diperoleh dianalisis dengan menggunakan regresi polinomial. Hasil penelitian yang diperoleh bahwa tinggi bibit, dan jumlah daun anggrek Dendrobium yang optimum dengan pemberianGrow Quick $L B \quad 1,5 \mathrm{cc}^{-1}$ air. Panjang daun optimum diperoleh dengan pemberian Grow Quick $L B$ dengan konsentrasi 0,3 cc/liter air. Lebar daun dan jumlah tunas optimum diperoleh dengan pemberian Grow Quick $L B$ dengan konsentrasi 0,2 $\mathrm{cc} \mathrm{l}^{-1}$ air.
\end{abstract}

Kata Kunci : Grow Quick LB, Dendrobium Sp. Konsentrasi.

\section{ABSTRACT}

The purpose of the research was to obtain concentration Grow Quick LB optimum for growth of seedlings of Orchid Dendrobium Sp.Environmental design used was complete Random Design. The design of the treatment given is concentration Grow Quick LBO $0 \mathrm{ccl}^{-1}$ water, $0.5 \mathrm{ccl}^{-1}$ water, $1 c c l^{-1}$ water, $1.5 \mathrm{l}^{-1}$ water, $2 \mathrm{ccl}^{-1}$ water, and $2.5 \mathrm{cc} \mathrm{l}^{-1}$ water.The data obtained were analyzed using polynomial regression. The research results obtained that the higher seed, and number of leaves of Dendrobium orchids with optimum pemberianGrow Quick $1.5 \mathrm{LB} c \mathrm{cl}^{-1}$. of water. Optimum leaf length is obtained by the giving Grow Quick LB with a concentration of $0.3 \mathrm{cc} \mathrm{l}^{-1}$ of water.The width of the leaves and shoots of the optimum amount is obtained by granting the Grow Quick LB with a concentration of $0.2 \mathrm{cc} \mathrm{l}^{-1}$ of water.

Keywords: Grow Quick LB, Dendrobium Sp. Cosentration

Diterima: 17 September 2018, disetujui: 27 September 2018

\section{PENDAHULUAN}

Anggrek merupakan salah satu dan pengembangannya didukung oleh bunga unggulan yang diproduksi Indonesia Pemerintah sebagai salah satu komoditas 
penting hortikultura. Permintaan akan bunga anggrek yang cenderung semakin meningkat menjadikan bunga anggrek menjadi salah satu komoditas penting dalam bidang hortikultura.

Pertumbuhan dan perkembangan anggrek dipengaruhi oleh kondisi lingkungan. Kondisi lingkungan ini dapat dibagi menjadi beberapa komponen yaitu iklim serta faktor lingkungan diantaranya adalahmedia tanam. Media tanam yang dikehendaki adalah media tanam yang dapat menyediakan unsur hara utuk memenuhi kebutuhan hidupnya.

Pemupukan merupakan salah satu cara untuk menunjang pertumbuhan dan perkembangan serta meningkatkan produktivitas tanaman. Surtinah (2017) melaporkan bahwa tanaman jagung manis yang diberi perlakuan pupuk melalui daun dan ditambah dengan zat pengatur tumbuh dapat meningkatkan pertumbuhan dan produksinya. Aplikasi pemupukan yang tepat pada anggrek menurut fase pertumbuhannya sangat diperlukan untuk mendukung pertumbuhan dan perkembangan anggrek. Komposisi yang diberikan harus seimbang antara unsur hara makro dan unsur hara mikro. Pada umumnya pupuk yang digunakan adalah pupuk cair yang diaplikasikan melalui daun karena lebih efisien dalam hal penyerapan unsur haranya

Unsur hara lebih mudah diserap oleh tanaman dalam bentuk cairan. Pupuk cair menyediakan nitrogen dan unsur mineral lainnya yang dibutuhkan untuk pertumbuhan tanaman (Surtinah \& Mutryarny, 2013). Pupuk NPK sering digunakan dalam pembibitan anggrek, bentuknya yang butiran dan padat menjadi kendala, dan untuk mengatasinya pupuk NPK dilarutkan terlebih dahulu, baru kemudian disemprotkan ke tanaman. Saat ini banyak beredar pupuk cair yang siap digunakan dengan kandungan unsur hara yang sama dengan NPK, dan penggunaannya lebih mudah. Salah satu pupuk yang dimaksud adalah Grow Quick $L B$.

Grow quick $L B \mathrm{k}$ adalah salah satu pupuk cair anorganik yang dapat digunakan untuk tanaman hias anggrek dendrobium. Grow quick $L B$ merupakan formula baru yang dibuat khusus untuk memacu tumbuh vegetatif dan memperbesar bentuk daun, merangsang pertumbuhan dan kesuburan tanaman.

Tanaman Anggrek Dendrobium adalah tanaman epifit, dimana perana akar tidak seperti pada tanaman lainnya, dan penyerapan unsur hara akan lebih efektif bila diberikan melalui daun, karena peranan akar yang sangat terbatas (Febrizawati, Murniati, \& Yoseva, 2014)

Tanaman anggrek dapat dipacu pertumbuhannya dengan memberikan pupuk yang diberikan melalui daun, karena pemupukan melalui daun untuk tanman anggrek lebih efisien dibandingkn pemupukan melalui media tanam (Yadi, Karimuna, \& Sabaruddin, 2012).

Kalium sangat berperan dalam proses metabolism tanaman. Kalium berperan dalam proses terbuka dan tertutupnya stomata, yang akan berpengaruh terhadap proses fotosintesis, bila kondisi $\mathrm{K}$ yang berkurang dalam sel penjaga maka stomata akan tertutup yang mengakibatkan fotosintat yang dihasilkan akan berkurang (Surtinah, 2010).

Grow Quick LB mengandung unsur hara makro dan mikro, dilengkapi dengan vitamin dan hormone pertumbuhan seperti Sitokinin yang sangat mempengaruhi proses pertumbuhan dan perkembangan sel tanaman. (Anonimous, 2012).

Berdasarkan hasil penelitian (Surtinah \& Mutryarny, 2013)bahwa pemberian pupuk Grow Quick LB 3 hari sekali merupakan pemberian terbaik, artinya kebutuhan bibit anggrek tersedia pada saat dibutuhkan dengan konsentrasi 3 cc/liter air.Tujuan penelitian ini adalah untuk mendapatkan konsentrasi Grow Quick LByang memberikan pertumbuhan 
bibit anggrek Dendrobium yang paling optimum. Tujuan penelitian adalah untuk mendapatkan konsentrasi Grow Quick LB

\section{BAHAN DAN METODE}

Penelitian ini dilaksanakan di Kelurahan Simpangtiga RW 09, RT 02 Pekanbaru selama 3 bulan mulai bulan Januari s/d Maret 2017.

Bahan-bahan yang digunakan dalam penelitian ini adalah bibit tanaman anggrek Dendrobium spyang berumur \pm 3 bulan, sabut kelapa, arang, pupuk Grow Quick LB, Dithane M-45, Dursban,. Alatalat yang digunakan adalah hand sprayer, ember, mistar, alat tulis dan jarum suntik.

Penelitian ini dilakukan secara eksprimen dengan menggunakan Rancangan Lingkungan Acak Lengkap dan perlakuan yang diuji ada 6 perlakuan dengan 6 kali ulangan, perlakuan tersebut adalah:

$\mathrm{G}_{0}=$ Tanpa Grow Quick $L B\left(0 \mathrm{cc} \mathrm{l}^{-1}\right.$ air $)$, $\mathrm{G}_{1}=$ Konsentrasi Grow Quick $L B$ 0,5 $\mathrm{cc}^{-1}$ air, $\mathrm{G}_{2}=$ Konsentrasi Grow Quick $L B$ 1,0 $\mathrm{cc} \mathrm{l}^{-1}$ air, $\mathrm{G}_{3}=$ Konsentrasi Grow Quick $L B$ $1,5 \mathrm{cc} \mathrm{l}^{-1}$ air, $\mathrm{G}_{4}=$ Konsentrasi Grow Quick $L B 2.0 \mathrm{cc} \mathrm{l}^{-1}$ air. $\mathrm{G}_{5}=$ Konsentrasi Grow Quick $L B$ 2,5 $\mathrm{cc} \mathrm{l}^{-1}$ air.

Data yang diperoleh dianaliis dengan menggunakan Regresi Polynomial dengan Persamaan garis sebagai berikut:

$$
y=a+b x+c x^{2}
$$

Dimana : $\mathrm{y}=$ Persamaan garis Regresi; $\mathrm{a}$ $=$ Hasil yang sebenarnya bila $\mathrm{x}=0$ ( titik potong di garis $\mathrm{y}) ; \mathrm{b}=$ Koefisien arah garis regresi; $\mathrm{x}=$ Nilai dari perlakuan

\section{Pelaksanaan Penelitian}

Persiapan Media Tanam, sabut kelapa dan arang direndam selama 2 minggu, air perendaman diganti setiap hari. Media arang dimasukkan $1 / 3$ bagian pot kemudian diberi sabut kelapa 1/3 bagian. yang optimum untuk pertumbuhan bibit anggrek Dendrobium Sp.

Pemasangan label dilakukan untuk mempermudah perlakuan yang diberikan dan sesuai dengan yang sudah ditetapkan berdasarkan rancangan lingkungan yang digunakan.

Bibit anggrek dipindahkan dari pot tunggal ke pot pembibitan yang lebih besar, selanjutnya pot yang sudah berisi bibit tersebut diletakkan di tempat penelitian sesuai dengan tata letak percobaan di lapangan.

Perlakuan diberikan pada bibit yang sudah berumur 3 bulandan konsentrasi Grow Quick LBsesuai dengan konsentrasi perlakuan, Grow quick LB diberikan dengan frekuensi 3 hari sekali.

\section{Pemeliharaan.}

Penyiraman dilakukan setiap hari pada pagi dan sore hari, dengan menggunakan handsprayer. Pengendalian hama dan penyakit, pengendalian hama dan penyakit dilakukan dengan menyemprotkan dithane M.45 sebanyak 1 gr $1^{-1}$ air. Pemberian pertama dilakukan 2 minggu setelah penanaman dengan interval 1 minggu sekali sampai akhir penelitian.

\section{Pengamatan}

Pengamatan dilakukan pada akhir penelitian. Yang di amati adalah sebagai berikut ; Tinggi bibit diukur dari pangkal sampai ke titik tumbuh batang dengan menggunakan penggaris; Jumlah daun dihitungadalah seluruh daun yang ada; Panjang daun diukur dengan menggunakan penggaris mulai dari pangkal hingga ke ujung daun secara vertikal. Daun yang diambil adalah daun terpanjang; Lebar daun diukur dengan mistar mulai dari sisi kiri ke sisi kanan secara horizontal. Lebar 
daun yang diukur adalah lebar daun terpanjang; Jumlah tunas adalah seluruh tunas yang muncul selama penelitian berlangsung, dengan kriteria sudah membentuk daun.

\section{HASIL DAN PEMBAHASAN}

Hasil penelitian diperoleh bahwa kepada bibit anggrek Dendrobium pupuk Grow Quick $L B$ yang diberikan menunjukan hasil sebagai berikut:
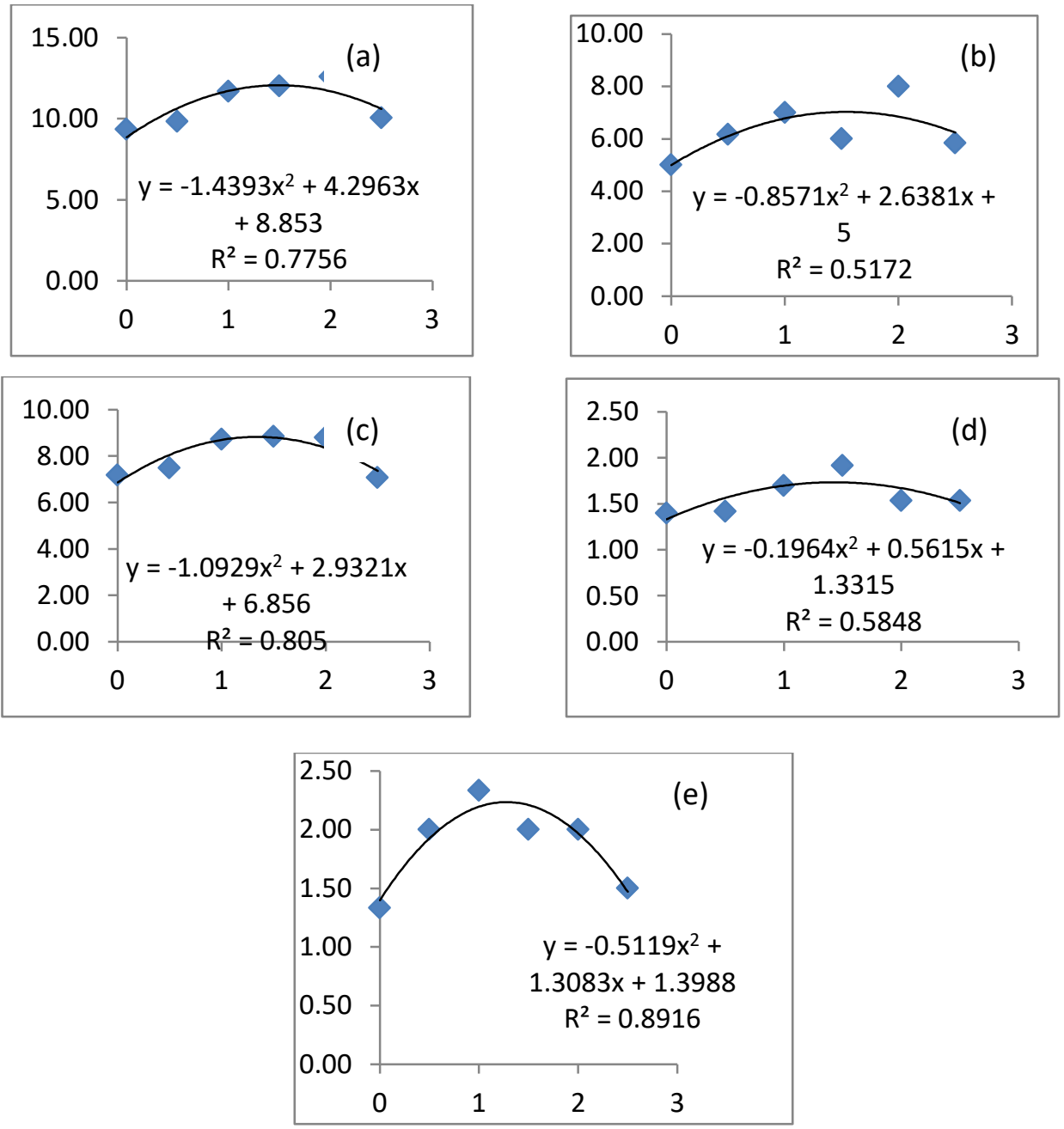

Gambar 1. (a) Tinggi Bibit (cm), (b) Jumlah Daun, (c)Panjang Daun (cm), (d) Lebar Daun $(\mathrm{cm})$, e). Jumlah Tunas (tunas)

Pada Gambar 1 a. Tinggi bibit Anggrek digambarkan dengan persamaan garis regresi $\mathrm{Y}=8,853+4,296 \mathrm{x}-1,439 \mathrm{x}^{2}$, dan $\mathrm{R}^{2}=78 \%$. Konsentrasi optimum Grow Quick $L B$ adalah 1,5 $\mathrm{cc}^{-1}$ air dan menghasilkan tinggi optimum bibit anggrek Dendrobium Sp. setinggi 12,06 $\mathrm{Cm}$ pada umur 4,5 bulan.(Andalasari, Yafisham, \& Nuraini, 2003) melaporkan bahwa anggrek dendrobium yang diberi Gandasil menghasilkan tinggi bibit 
setinggi 24,39 helai pada anggrek yang berumur 6 bulan.

Jumlah daun bibit anggrek Dedrobium Sp. yang optimum adalah pada konsentrasi $1,5 \mathrm{cc}^{-1}$ air, dengan jumlah daun $=7,03$ helai, digambarkan dengan persamaan garis regresi $\mathrm{Y}=5+2,638 \mathrm{x}-$ $0,857 \mathrm{x}^{2}$, dan $\mathrm{R}^{2}=52 \%$. Penanaman anggrek dendrobium dengan menggunakan media tanam pakis, arang sekam, dan sabut kelapa ditambah dengan pemupukan Growmore menghasilkan jumlah daun terbanyak yaitu 3,83 helai (Febrizawati et al., 2014).

Gambar 1 c. Memperlihatkan bahwa panjang daun bibit anggrek Dendrobium $S p$. yang optimum diperoleh pada konsentrasi Grow Quick LB 0,3 cc/liter air dan panjang daun optimum yaitu 9,06 $\mathrm{Cm}$, yang diturunkan dari persamaan garis regresi $\mathrm{Y}=6,856+2,932$ $\mathrm{x}-1,092 \mathrm{x}^{2}$, dan $\mathrm{R}^{2}=81 \%$. Seperti yang dilaporkan oleh (Bakrie, 2005) bahwa terjadi penambahan panjang daun ketiga sepanjang $1,35 \mathrm{~cm}$ akibat pemberian Hortigro sebanyak $1,5 \mathrm{cc} \mathrm{liter}^{-1}$.

Konsentrasi optimum Grow Quick $L B$ 0,2 cc/liter air menghasilkan lebar daun bibit anggrek Dendrobium Sp. optimum yaitu $1,79 \mathrm{Cm}$, hasil optimum ini diperoleh berdasarkan persamaan garis regresi $\mathrm{Y}=$ $1,331+0,561 \mathrm{x}-0,196 \mathrm{x}^{2}$, dan $\mathrm{R}^{2}=58 \%$.

Grow Quick $L B$ dengan konsentrasi $0,2 \mathrm{cc}^{-1}$ air, menghasilkan jumlah tunas optimum yaitu 2,20 tunas. Angka tersebut diperoleh melalui persamaan garis regresi $\mathrm{Y}=1,398+1,308 \mathrm{x}-0,511 \mathrm{x}^{2}$, dan $\mathrm{R}^{2}=$ $89 \%$ pada umue 4,5 bulan. Bibit anggrek yang diberi Gandasil B dapat menghasilkan anakan sebanyak 3,83 pada umur enam bulan,(Andalasari et al., 2003) melaporkan pertumbuhan dan perkembangan bibit anggrek disebabkan karena unsur hara makro dan mikro yang terdapat pada Gandasil B dan Grow Quick LB dapat memacu percepatan pertumbuhan bibit anggrek dendrobium tersebut.

Hasil yang diperoleh dari analisis regresi menunjukan Grow Quick LB (GQLB) berperan dalam meningkatkan pertumbuhan bibit Anggrek Dendrobium $S p$. hal ini disebabkan karena kandungan nutrisi di dalam Grow Quick $L B$, tidak hanya unsur hara saja tetapi juga mengandung zpt sitokinin dan Vitamin B1, yang berperan dalam proses pembelahan sel. Semakin banyak sel yang terbentuk berarti proses pertumbuhan dan perkembangan tanaman berlangsung dengan optimal. Anonimous (2012) melaporkan bahwa pembelahan sel dan pertumbuhan sel pada bibit anggrek dapat disebabkan karena vitamin B1 (Thiamin) dapat mempengaruhi pembelahan sel pada organ daun.

Surtinah dan Mutryarny (2013) melaporkan bahwa sitokinin yang terkandung dalam GQLB mempengaruhi proses pertumbuhan dan perkembangan bibit anggrek pada stadia kompot. Pertumbuhan dan perkembangan sel sangat erat kaitannya dengan prose pembelahan sel, pembesaran sel dan pemanjangan sel.

\section{SIMPULAN}

Konsentrasi GQLB untuk menghasilkan tinggi bibit, dan jumlah daun anggrek Dendrobium yang optimum adalah $1,5 \mathrm{cc} \mathrm{l}^{-1}$ air. Panjang daun optimum diperoleh dengan pemberian $1^{-1}$ air. 


\section{DAFTAR PUSTAKA}

Andalasari, T. D., Yafisham, dan Nuraini. 2003. Respon Pertumbuhan Anggrek

Dendrobium Terhadap Jenis Media Tanam Dan Pupuk Daun Respon Pertumbuhan Anggrek Dendrobium Terhadap Jenis Media Tanam Dan Pupuk Daun, 14(1), 76-82.

Anonimous. 2012 Tumbuh Extra Cepat, Grow Quick Solusi Tepat Bertani Organik dan Anorganik. Retrieved

Bakrie, A. H. 2005. Pertumbuhan Vegetatif Tanaman Anggrek Dendrobium ( Dendrobium sp .) Pada Aplikasi Zeolit Sebagai Campuran Media, 7(1), 53-60.

Febrizawati, Murniati, dan Yoseva, S. 2014. Pengaruh Komposisi Media Tanam Dengan Konsentrasi Pupuk Cair Terhadap Pertumbuhan Tanaman Anggrek Dendrobium (Dendrobium sp.) THE, 1(2), 248249.
Surtinah. 2010. Agronomi Tanaman Budidaya. Pekanbaru: Alaf Riau.

Surtinah, S., dan Mutryarny, E. (2013). Frekuensi Pemberian Grow Quick Lb Terhadap Pertumbuhan Bibit Anggrek Dendrobium Pada Stadia Komunitas Pot. Jurnal Ilmiah Pertanian, 10(2), 31-40.

Surtinah, S. 2017. Potensi Hasil Jagung Manis (Zea mays saccharata, Sturt) Dengan Pemberian Paket Teknologi Pupuk Dan Zat Pengatur Tumbuh. Jurnal BiBieT, 2(1), 37-44.

Yadi, S., Karimuna, L., dan Sabaruddin, L. 2012. P Engaruh P Emangkasan Dan $\mathrm{P}$ Emberian $\mathrm{P}$ Upuk $\mathrm{O}$ Rganik $\mathrm{T}$ Erhadap $\mathrm{P}$ Roduksi Tanaman $\mathrm{M}$ entimun ( Cucumis sativus L.) Effects of Pruning and Organic Fertilizer on the Yield of. Berkala PENELITIAN AGRONOMI, 1(2), 107-114. 